\title{
The acquired immune deficiency syndrome and epidemic of infection with human immunodeficiency virus: costs of care and prevention in an inner London district
}

\author{
ANNE M JOHNSON, MICHAEL W ADLER, JUNE M CROWN
}

\begin{abstract}
The epidemic of the acquired immune deficiency syndrome (AIDS) and infection with human immunodeficiency virus (HIV) necessitates early planning of services and allocation of resources. The use of hospital resources by patients with AIDS and the planned additional costs of clinical and preventive services for the epidemic of infection with HIV were calculated for an inner London health district that has treated $18 \%$ of the cases in the United Kingdom. Patients with AIDS required on average $\mathbf{5 0}$ days of inpatient hospital care each at an estimated current average lifetime cost of $\$ 6800$. These costs, however, underestimated the additional capital and revenue costs of planned new preventive and treatment services, estimated as being $£ 388000$ revenue and $£ 472000$ capital for 1986-7.

It is important to invest now in preventive services throughout the United Kingdom to reduce the future social and financial costs of AIDS.
\end{abstract}

\section{Introduction}

Professional and public opinion has recently drawn attention to the need for health care planning and financing for the acquired immune deficiency syndrome (AIDS) and the underlying epidemic

\footnotetext{
Academic Department of Genitourinary Medicine, Middlesex Hospital Medical School, London W1N 8AA

ANNE M JOHNSON, MRCGP, lecturer

MICHAEL W ADLER, MD, FRCP, professor

Department of Community Medicine, Bloomsbury Health Authority JUNE M CROWN, FFCM, district medical officer

Correspondence to: Professor Adler.
}

of infection with human immunodeficiency virus (HIV) (this virus was previously known as human $\mathrm{T}$ lymphotropic virus type III (HTLV-III) or lymphadenopathy associated virus (LAV)). ${ }^{1.3}$ The resource costs of AIDS and infection with HIV go far beyond those required for inpatient and outpatient care and include those required for preventive strategies, whether national or local, collective or individual. They also include the costs of screening blood donations for HIV antibody; heat treating blood products; upgrading laboratory facilities; providing dental services for patients positive for HIV antibody; tightening up policies to control infectious diseases; and training staff.

There is evidence that the spread of HIV has been rapid in high risk groups, particularly in London. ${ }^{+8}$ Health care planning for AIDS and infection with HIV is hampered, however, by lack of information about the size of the populations at high risk. It is evident that those who have been infected by the virus greatly outnumber those with AIDS, and an estimated 10 000-20000 people are already infected in the United Kingdom. ${ }^{9}$ Their prognosis is uncertain because the true length of the incubation period from infection to the appearance of AIDS is not yet known and may, when the clinical course of the disease is fully understood, turn out to be longer than was initially thought ${ }^{1011}$ (D N Lawrence $e t a l$, international conference on AIDS, Atlanta, Georgia, April 1985). This means that current estimates of the proportion of people with infection with HIV who will eventually develop AIDS may be too low. In a study of five cohorts of patients infected by HIV the three year incidence of AIDS ranged from $8 \cdot 1 \%$ to $34 \cdot 2 \%$. $^{12}$

In view of the projected increase in the number of cases of AIDS ${ }^{13}$ and in the underlying pool of HIV infection regions and districts will need to plan their services and allocate appropriate resources. Bloomsbury Health District, in inner London, has treated $18 \%$ of the cases of AIDS in the United Kingdom to date. We present our estimates of the costs of services that have been provided for these patients and attempt to identify the information necessary for planning preventive and treatment services and resource allocation for this condition. 


\section{Resource use by patients with AIDS}

Thirty three cases of AIDS (as defined by the Centers for Disease Control) treated in Bloomsbury hospitals to the end of June 1985 were available for analysis. Fifteen patients had Kaposi's sarcoma, 11 Pneumocystis carinii pneumonia, four Kaposi's sarcoma and $P$ carinii pneumonia, and three other opportunistic infections. The resources used by these patients were estimated by extracting data retrospectively from hospital inpatient and outpatient notes, using a structured form. Twenty nine of the 33 patients received inpatient hospital care. For each case the number of admissions and length of stay were recorded. The total number of weeks under the supervision of the hospital, defined as the time from presentation with symptoms leading to a diagnosis of AIDS to death, transfer to another district, or completion of this study was also recorded.

A total of 67 hospital admissions were recorded for the 29 inpatients, accounting for 1155 hospital inpatient days. Mean length of stay was $17 \cdot 2$ days (median 13, range $1-54$ days). Of the 67 admissions, three were for intensive care, with an average length of stay of 10 days. Twenty seven patients received all their treatment in the district, accounting for a total of 949 weeks of follow up and occupying on average $1 \cdot 1$ bed days per week of follow up.

For 16 of the 33 cases the "lifetime" use of resources could be estimated as they had been followed up from diagnosis to death. These patients were followed up for a mean of 22.4 weeks (median 22.5, range 1.47 weeks), during which they occupied a mean of 50 (median $47 \cdot 5$, range 4-108) bed days each. Four died at home. Ten required bronchoscopy, six sigmoidoscopy, two gastroscopy, and two colonoscopy. Two required lymph node biopsy and three required other operations necessitating general anaesthesia.

The figure shows trends in bed use by the 29 patients admitted in the district from March 1983 to June 1985 . By June 1985 average bed occupancy was 2.5 beds but maximum bed occupancy was five beds. Mean bed occupancy taken alone underestimates the impact of AIDS on inpatient care.

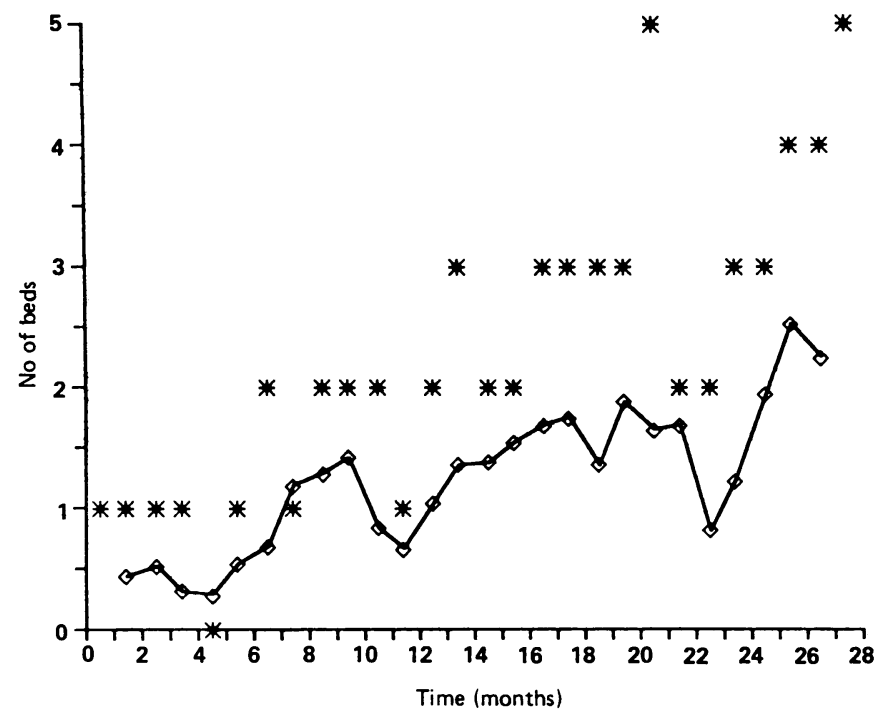

Bed occupancy by patients with AIDS, March 1983 to June 1985. ${ }^{\star}=$ Maximum number of beds occupied. $\diamond=$ Mean bed occupancy (three month moving average).

\section{AVERAGE LIFETIME COST PER CASE}

Costing in the NHS is hampered by the absence of billing systems and clinical budgeting. The heterogeneity of clinical problems in patients with AIDS means that resource use varies widely. In view of the small sample size we did not attempt to analyse resource use by diagnostic category.

Length of stay is an important measure of resource use in terms of inpatient care of patients with AIDS. Nearly $80 \%$ of the cost of inpatient care is fixed, medium term costs for such things as staff already employed, administration, cleaning and portering, and estate management. ${ }^{1+}$ Some of the cost of drugs and investigations also relates to fixed staff costs. Treatment of opportunistic infection in patients with AIDS generally requires fairly inexpensive antibiotics, though some patients have received more costly drugs as part of research programmes; these last were not included in our calculations.

The average cost of an inpatient day in the teaching hospital where these patients were treated was $£ 126.15$ (1984-5 prices; Bloomsbury Health Authority cost statements 1984-5). This compares with the average cost of $£ 111.43$ in a London teaching hospital and $£ 97.78$ in a provincial teaching hospital in England. ${ }^{15}$ The total cost of the 1155 days of inpatient care was therefore $£ 145700$. The average lifetime cost for patient with AIDS managed on general medical wards based on 50 days of inpatient care was therefore $£ 6308$. The average lifetime cost of outpatient care on the basis of $10 \cdot 2$ visits per case over a mean of 22.4 weeks amounted to $£ 530$ (Bloomsbury Health Authority cost statements 1984-5). Thus the total cost of lifetime hospital care on the basis of current patterns amounted to $£ 6838$.

\section{Planning future preventive and treatment services}

\section{DEMAND FOR SERVICES}

To assess likely demand for future services we estimated the size of high risk groups currently using the service.

Homosexual and bisexual men-Clinic statistics for Bloomsbury district for 1984 recorded 7700 cases of sexually transmitted diseases in homosexual and bisexual men. Belsey and Adler calculated that each patient accounted for 1.4 cases, ${ }^{16}$ giving an estimate of 5500 homosexual and bisexual men attending the clinics each year. At least $21 \%$ (1155) of these men were seropositive for HIV antibody in mid-1984,,$^{5}$ and the proportion now is probably higher.

Intravenous drug users-Hartnoll et al, on the basis of a study in Camden and Islington (part of which is in Bloomsbury), estimated that there were 20000 regular opiate users in Greater London in 1982. ${ }^{17}$ Many are not known to the health services, but roughly 1000 regular users contact specialist health or social services in any one year in the district ( $R$ Hartnoll, personal communication).

Other groups-People concerned about heterosexual transmission are presenting for advice. Routine recording of patients attending one of the sexually transmitted diseases clinics primarily for advice about AIDS began in May 1985. Of the first 458 people who attended, 327 were homosexual men, 51 bisexual men, 53 heterosexual men, and 27 heterosexual women. Demand may be considerably increased if policies for the control of infectious diseases include HIV antibody testing with informed consent before operations. Finally, 200 tests a year will be needed for members of blood donor panels and haemophiliacs.

In summary, in any one year in the district a minimum of 6700 people are readily identifiable as likely to present for information or to require HIV antibody testing.

\section{INFORMATION AND COUNSELLING}

In the absence in the foreseeable future of a simple preventive strategy for infection with HIV, such as a vaccine, prevention has to rely on changes in behaviour. Guidelines published by the Department of Health and Social Security stated that HIV antibody testing and counselling should be available through general practitioners and sexually transmitted diseases clinics. ${ }^{18}$ A consultation provides an opportunity for the clinician or counsellor to offer practical guidelines (for example, safer sex practices) on reducing risks of acquiring or transmitting the virus, as well as providing psychological support. The role of the antibody test in this process is not clear as the advice to people at high risk will often be the same whether they are infected or not.

On the basis of the demand outlined above existing health advisers will take on part of the preventive work; the table $(A)$ shows the additional costs to a district service of providing testing, laboratory support, health information, and counselling.

\section{INPATIENT SERVICES}

The marginal cost (that is, the extra cost of treating one more case) may be small at the start of an epidemic, when one or two cases can be managed on existing medical wards. This cost increases substantially, however, when it becomes necessary to invest in extra staff or equipment to deal with the problem.

As pressure on side wards, where patients with AIDS have been managed, increased in the district plans were made for a dedicated facility to provide a comprehensive service for these patients. Because of the requirement for endoscopic investigations units treating many patients with AIDS may need dedicated equipment to overcome problems of sterilisation. Estimates of length of stay were used in a queuing model, assuming random arrivals. ${ }^{19}$ Future admission rates were based on exponential projections of rates recorded to June 1985. This model projected a mean bed occupancy of $5 \cdot 2$ beds by March 1986 and $90 \%$ maximum bed occupancy of eight beds. On 
this basis a six bedded ward was initially planned and costed, rising to eight beds by mid-1986. The staffing costs of this ward were based on nursing dependency for single rooms, which is higher than that used on a general medical ward. The table $(B)$ summarises the costs.

Estimated additional costs incurred by district in providing services for patients with AIDS and infection with HIV $1986-7$

\begin{tabular}{lcc}
\hline & Revenue & Capital \\
\hline A: HIV antibody testing and counselling & $11 \cdot 5$ & \\
1 Counsellor & $13 \cdot 9$ & \\
l Clinical psychologist & $10 \cdot 4$ & \\
1 Clerical officer & $18 \cdot 5$ & \\
2. Medical laboratory scientific officers & $25 \cdot 0$ & $25 \cdot 5$ \\
Antibody tests & & $57 \cdot 1$ \\
Office/health education equipment & & 82.6 \\
Building alterations & & \\
& & \\
& &
\end{tabular}

B: Inpatient services (6-8 bedded ward)

1 General medical registrar

13 Nurses*

Domestic services

Consumable costs

Blood gas machine

Endoscopes

Ward adaptation

\begin{tabular}{rr}
18.6 & \\
$131 \cdot 6$ & \\
$8 \cdot 1$ & \\
36.8 & \\
& $13 \cdot 0$ \\
& 30.9 \\
& $15 \cdot 0$ \\
\hline $195 \cdot 1$ & 58.9 \\
\hline
\end{tabular}

C: Outpatient treatment

1 Senior registrar (genitourinary medicine)

1 Senior

2 Nurses
Drugs/equipment

$\begin{array}{r}18 \cdot 9 \\ 18 \cdot 6 \\ 26 \cdot 0 \\ \hline 63 \cdot 5\end{array}$

D: Dental services

1 Clinical assistant

2 Surgery assistants

Domestic costs

Patient variables

Dedicated chair/equipment

\begin{tabular}{rr}
$19 \cdot 6$ & \\
$13 \cdot 4$ & \\
$2 \cdot 0$ & \\
$5 \cdot 0$ & \\
& $25 \cdot 0$ \\
\hline $40 \cdot 0$ & $25 \cdot 0$ \\
\hline
\end{tabular}

E: Pathology Services

Chemical pathology

Medical microbiology

Histopathology

Haematology

Staff and consumables

F: Total costs $120 \cdot 3$

* Based on nursing dependency for single rooms.

† Based on higher estimate of $75 \%$ occupancy of eight bedded ward

\section{OUTPATIENT TREATMENT SERVICES}

Those in high risk groups may elect not to undergo antibody testing, but many of those infected by the virus will at some time require medical follow up. In a San Francisco cohort, for every case of AIDS there were 8.6 people with generalised lymphadenopathy or prodomal symptoms, while $41 \%$ of those who seroconverted developed either AIDS or related conditions over a follow up period of up to six years. "Though we accept the considerable problems of predicting numbers of cases, if the district continues to see $18 \%$ of the epidemic then a "best estimate" of 54 patients with AIDS will be alive and requiring treatment at the end of $1986 .{ }^{13}$ In addition as many as 900 symptomatic seropositive patients may require follow up. On the basis of fortnightly follow up for patients with AIDS and three monthly follow up for seropositive patients this would require 96 outpatient visits a week. The table $(C)$ shows estimated costs of additional outpatient services required.

\section{DENTAL SERVICES}

British guidelines have advocated that precautions as for hepatitis B should be taken for dental care and that people positive for HIV antibody should inform dentists of their seropositivity." In practice, seropositive patients may find their general dental practitioner unwilling to treat them.
Implementation of precautions is time consuming, and districts treating many seropositive patients will need to consider whether to provide dedicated facilities. The table $(D)$ shows the estimated cost of providing a full time service to meet the needs in this teaching district.

\section{PROTECTION AND EDUCATION OF STAFF AND UPGRADING OF LABORATORIES}

Worldwide concern has been expressed about precautions to be taken by staff dealing with patients infected with HIV. Pooled evidence suggests that the risk of nosocomial infection is small, ${ }^{21}$ but staff require information updates and training in policy for controlling infectious diseases. Interim guidelines of the Advisory Committee on Dangerous Pathogens set out standards of protection for laboratories working with material infected with HIV. ${ }^{22}$ In particular, they recommend category III containment in laboratories dealing with large numbers of infected specimens. The table $(E)$ shows estimates of the cost of upgrading district laboratories to standards recommended by the committee.

\section{TOTAL COSTS}

The table $(F)$ summarises the estimated additional costs of a comprehensive service in the district for 1986-7. This amounts to a capital cost of $£ 287000$ and a revenue cost of $£ 388000$.

\section{Discussion}

This study aimed to provide preliminary information and principles for planners who have to prepare for the future impact of infection with HIV on health services, though we recognise that the details presented here are specific to a London teaching district. The management of patients with AIDS is only a part of the problem. Estimates of lifetime resource use by patients with AIDS that are based on early cases may be underestimates, as they will tend to select disproportionately patients with shorter survival times (though not necessarily with less inpatient requirements). Costing could alternatively be based on bed days per week of treatment related to mean survival but would be biased towards higher estimates as bed use is higher in the terminal phase of illness. We emphasise that the average costings relate to current practices and ignore the higher marginal costs that would be imposed by greater nursing dependency and capital investment if new inpatient facilities were established. They also ignore costs of community health voluntary and social services. Home care was organised through existing district nurses, social services, and a home terminal care team. In future the district may consider employing a community nurse to facilitate coordination of hospital and home care.

Scitovsky et al reported a lifetime average of 28.6 inpatient days from diagnosis to death in San Francisco (international conference on AIDS, Georgia, April 1985) compared with 50 in this study, although this study included days spent in hospital for investigation before firm diagnosis. The average lifetime cost per case not requiring intensive care was $\$ 24000$ in San Francisco. This is equivalent to $£ 13032$ at 1983 exchange rates and parity of purchasing power. ${ }^{23}$ Hurst estimated on the basis of 1977 figures that the unit cost for short stay admissions was $2 \cdot 3$ times higher in the United States than in England, even though length of stay per admission was longer in England. ${ }^{24}$ Thus the current cost estimate of $£ 6838$ in this study seems to be broadly compatible with findings of the San Francisco study.

Hardy et al estimated much higher lifetime costs per case,,$^{2-}$ but these were based on the assumption that the length of stay per admission was 31 days, which is much higher than the observed value of 11.4 days in San Francisco and 17.4 days in this study. The lower figure in San Francisco may reflect the substantial efforts that have been made in that city to coordinate inpatient, outpatient, community, and terminal care, which may reduce the time that a patient needs to stay in hospital. Planners in this country will have to consider financial investment in care outside hospital, and alternative options for care, including home and hospice care, require 
costing. The establishment of a dedicated ward will make more accurate marginal costing possible.

Of the 67 admissions in this study, only three were for intensive care, in contrast to American experience. ${ }^{26}$ Recent evidence suggests that the outcome for patients admitted to intensive treatment units is poor ${ }^{27}$ and this may explain the infrequent use of such units in this study.

Our costings are based on the district's present services and staff. For example, the proposal to employ additional junior rather than consultant medical staff reflects the fairly high proportion of senior staff in the district. The plan outlined here was submitted to the North East Thames Regional Health Authority, which allocated the district $£ 600000$ towards $1986-7$ costs from money set aside by the Department of Health and Social Security for AIDS.

McEvoy and Tillett estimated that in 1986, 336 new cases of AIDS would be reported if the epidemic continued to increase at its current rate. ${ }^{13}$ At 50 bed days per case this would require a total of 16800 bed days, the equivalent of 46 beds fully occupied for one year. To date over three quarters of the cases of AIDS have been reported from the four Thames regions, and most have been managed in hospitals in inner London ( $M$ McEvoy, personal communication). The demand for services has therefore been mainly in those districts subject to revenue reductions in accordance with the Resource Allocation Working Party policy. This highlights the problem for such districts: they will have to choose to reduce other services, forgo service developments, or offer different or cheaper services to patients infected with HIV if the resource requirements are not assessed and the service funded. The adapted AIDS ward in Bloomsbury will be one that would otherwise be closed to achieve financial savings.

While investment in services is made now in inner London, districts throughout the country will need to consider the costbenefit equation of investing in primary prevention now rather than bearing the social and financial costs of future cases of AIDS. In our own district, we should perhaps shift more resources to controlling the epidemic. The annual salary of one health educator/counsellor employed full time in the prevention of HIV is less than the cost of treating two cases of AIDS on our conservative estimates. In San Francisco and New York massive resources have been put into health education and sexual behaviour is changing. ${ }^{289}$ Because the probability of acquiring the virus from one encounter increases as the prevalence increases in the community behaviour change may not occur early enough in the epidemic to reduce the incidence of new infections. ${ }^{29}$ The crucial question remains whether we are at an early enough stage in the epidemic in the United Kingdom for preventive strategies to reduce the future toll of disease. This is no longer a question of "sooner rather than later" but of "yesterday rather than today."
We thank Peter Large and Peter West for advice on costing and Victoria Treble for secretarial work.

\section{References}

1 Mortimer PP. Estimating AIDS UK. Lancet 1985;ii: 1065

2 Searle ES. AIDS predicting and planning. Lancet 1985 ;ii: 1064

3 Anonymous. AIDS: needed a resolute response [Editorial]. Guardian 1985 November 6:10. 4 Mortimer PP, Jesson WJ, Vandervelde EM, Pereira MS. Prevalence of antibody to human T lymphotropic virus type III by risk group and area, United Kingdom 1978-84. Br Med $\mathcal{J}$ $1985 ; 290: 1176-8$

5 Carne CA, Weller IVD, Sutherland S, et al. Rising prevalence of human T-lymphotropic virus type III (HTLV-III) infection in homosexual men in London. Lancet 1985; ii: 1261-2.

6 Jones P, Hamilton PJ, Bird G, et al. AIDS and haemophilia: morbidity and mortality in a well defined population. Br Med f 1985;291:695-9.

Mortimer PP, Vanderwelde EM, Jesson WJ, Pererra MS. HTLV-III antibody in Swiss and English intravenous drug abusers. Lancet 1985; ii:449-50.

8 Peutherer JF, Edmond E, Simmonds P, et al. HTLV-III antibody in Edinburgh drug addicts. Lancet 1985;ii:1129.

9 Anonymous. AIDS in the UK [Editorial]. Lancet 1985; $; i: 1103-5$

10 Curran JW, Lawrence DN, Jaffe H. Acquired immunodeficiency syndrome (AIDS) associated Curran JW, Lawrence DN, Jaffe H. Acquired imm
with transfusions. N Engl J Med 1984;310:69-75.

11 Jaffe $\mathrm{HW}$, Darrow WW, Echenberg DF, et al. The acquired immunodeficiency syndrome in a cohort of homosexual men. Ann Intern Med 1985;103:210-4.

2 Goedert JJ, Biggar RJ, Weiss SH, et al. Three-year incidence of AIDS in five cohorts of HTLV III-infected risk group members. Science 1986;231:992-5.

$13 \mathrm{McEvoy} \mathrm{M}$, Tillett $\mathrm{H}$. Some problems in the prediction of future numbers of cases of acquired immunodeficiency syndrome in the UK. Lancet 1985;ii:541-2.

14 Department of Health and Social Security. Health care and its costs. The development of the National Health Service in England. London: HMSO, 1983.

15 Department of Health and Social Security. Health and personal social services statistics for England 1985. London: HMSO, 1985.

16 Belsey EM, Adler MW. Study of STD clinic attenders in England and Wales 1978: 1. Patients versus cases. Br $\mathcal{J}$ Vener Dis 1981;57:285-9.

17 Hartnoll R, Mitcheson M, Lewis R, Bryer S. Estimating the prevalence of opioid dependence. Lancet 1985; ;:203-5.

18 Department of Health and Social Security. AIDS booklet 2. Information for doctors concerning the introduction of the HTLV-III antibody test. London: DHSS, 1985.

19 IBM, Analysis of some queuing models in real-time systems. Data processing techniques. White Plains, New York: IBM, 1969.

20 Department of Health and Social Security. AIDS booklet 3. Guidance for surgeons, anaesthetists, dentists and their teams in dealing with patients infected with HTLV-III. London: DHSS, 1986.

21 Anonymous. Update: evaluation of human T-lymphotropic virus type III/lymphadenopathy associated virus infection in health care personnel-United States. MMWR 1985;34:575-8.

22 Advisory Committee on Dangerous Pathogens. Acquired immune deficiency syndrome (AIDS) interim guidelines. London: Department of Health and Social Security and Health and Safety Executive, 1984.

23 Anonymous. National accounts 1960-83. Vol I. Paris: Office of Economic Cooperation and Development, 1984.

24 Hurst J. Financing health services in the US, Canada and Britain. London: King's Fund, 1985. (Nuffield/Leverhulme fellowship report.)

25 Hardy AM, Rausch KJ, Curran JW. The economic impact of the first 10,000 cases of AIDS in the United States. JAMA 1985;255:209-11.

26 Groopman JE, Detsky AS. Epidemic of AIDS: a need for economic and social planning. Ann Intern Med 1983;99:259-61.

27 Murray JF, Felton CP, Garay SM, et al. Pulmonary complications of the acquired immune deficiency syndrome. $N$ Engl f Med 1984;25:1682-7.

28 Anonymous. Designing an effective AIDS prevention campaign strategy for San Francisco: results from the second probability sample of an urban gay male community. San Francisco: San Francisco AIDS Foundation Research and Decisions Corporation, 1985.

29 Stevens CE, Taylor PE, Zang EA, et al. Human T-cell lymphotoropic virus type III infection in a cohort of homosexual men in New York city. JAMA 1986;255:2167-72.

(Accepted 27 May 1986)
A 64 year old patient in good health has macular degeneration of the retina which has made her left eye useless for reading. Can anything be done to preserve the right eye or postpone similar degeneration?

Age related senile macular degeneration is the commonest cause of registrable blindness in England. ${ }^{1}$ Two main types of senile macular degeneration are recognised: disciform ("exudative") degeneration and geographic atrophy of the pigment epithelium ("dry" degeneration). Disciform senile macular degeneration is caused by the invasion of the subretinal space by choroidal new vessels and results in serous elevation of the retina, subretinal haemorrhage, and eventually scarring; loss of central vision is rapid and often profound. On the other hand, geographic atrophy of the pigment epithelium is slower in onset and is generally less disabling than disciform senile macular degeneration. Recently published results of treatment trials of disciform senile macular degeneration from Moorfields and from other centres have shown that the destruction of the new vessels by laser photocoagulation is beneficial so long as the new vessels do not extend under the centre of the fovea (point of fixation). ${ }^{2-4}$ Natural history studies have shown that patients with disciform senile macular degeneration in one eye are likely to develop a similar lesion in the other eye at a rate of $12-15 \%$ a year. ${ }^{5}$ When this happens the macular area becomes raised by serous fluid and the patient experiences distortion of vision often before central vision deteriorates.
No preventive measures or drugs have been shown to be of benefit; however, patients such as this woman are advised to look carefully for any distortion of straight lines (such as window frames, crossword puzzles, etc) and to report any such changes immediately. Rapid referral to an ophthalmologist is essential, as over $50 \%$ of patients seen within two to three weeks of the onset of their symptoms can be treated. ${ }^{6}$ Unfortunately, such is the usual delay in referral that only $5-10 \%$ of patients seen in the British ophthalmic centres are currently regarded as suitable for treatment. Clearly, increased awareness of the problem by the medical and lay public would improve the prognosis in this large and growing number of patients.ZDENEK J GREGOR, consultant ophthalmic surgeon, London.

1 Sorsby A. The incidence and causes of blindness in England and Wales 1948-62. London: HMSO, 1966.

2 Moorfields Macular Study Group. Treatment of senile disciform macular degeneration: a singleblind randomised trial by argon laser photocoagulation. Brf Ophthalmol 1982;66:745-53.

3 Macular Photocoagulation Study Group. Argon laser photocoagulation for senile macular degeneration: results of a randomized clinical trial. Arch Ophthalmol 1982;100:912-8.

4 Coscas G, Soubrane G. Photocoagulation des neovaisseaux soux retiniens dans la degenerescence maculaire senile par le laser a argon: resultats de l'etude randomisee de 60 cas. Bull Soc Ophthalmol $F_{r}$ (in press).

5 Gregor Z, Bird AC, Chisholm IH. Senile disciform degeneration in the second eye. Br J Ophthalmol 1977;61:141-7.

6 Grey RHB, Bird AC, Chisholm IH. Senile disciform macular degeneration: features indicating suitability for photocoagulation. Br J Ophthalmol 1979;63:85-9. 